\title{
Interferência de plantas daninhas no crescimento da cultura do trigo
}

\section{Josiane Costa Maciel ${ }^{1}$, José Barbosa dos Santos ${ }^{1}$, Ricardo Felix dos Reis ${ }^{1}$, Evander Alves Ferreira ${ }^{1}$, Gustavo Antônio Mendes Pereira ${ }^{2}$}

${ }^{1}$ Universidade Federal dos Vales do Jequitinhonha e Mucuri, Campus JK, Diamantina, Minas Gerais, Brasil. E-mail: josi413@hotmail.com,jbarbosasantos@yahoo.com.br, ricardo_freis@yahoo.com.br, evanderalves@gmail.com,

${ }^{2}$ Universidade Federal de Viçosa, Campus Viçosa, Viçosa, Minas Gerais, Brasil. E-mail: gustavogamp@ hotmail.com

Recebido: 13/03/2016; Aceito:21/06/2017.

\section{RESUMO}

Dentre os fatores que limitam a expressão do potencial produtivo da cultura do trigo a competição com as plantas daninhas é um dos mais severos causando grandes prejuízos à produtividade e qualidade da produção. Dessa forma, o estudo teve como objetivo avaliar o efeito da competição das espécies E. fosbergii, B. pilosa e G. parviflora, isoladas e em associação no crescimento das plantas de trigo em condição de campo. Para isso, as plantas foram semeadas em diferentes densidades: 0; 23; 46 e 66 plantas daninhas $\mathrm{m}^{-2}$, convivendo com a cultura por 85 dias após a semeadura. As plantas daninhas apresentaram diferentes interferências sobre as variáveis agronômicas e cada espécie competiu com a cultura por diferentes nutrientes. A cultura do trigo é afetada negativamente quando cultivada sob infestação de E. fosbergii e G. parviflora em densidades crescentes, destacando-se que essas espécies daninhas são adaptadas a temperaturas mais baixas.

Palavras-chave: Bidens pilosa, Emilia fosbergii, Galinsoga parviflora, potencial competitivo.

\section{Weed community on the growth of wheat crop}

\begin{abstract}
Among the factors that limit the expression of the productive potential of the wheat crop competition with weeds is one of the most severe, result in damage to the productivity and quality of production. Thus, this study aimed to evaluate the effect of competing species Emilia fosbergii, Bidens pilosa and Galinsoga parviflora, as well as the association of the three species in the growth of wheat plants under field conditions. For this, plants were seeded in different densities: $0 ; 23 ; 46$ and 66 weeds $\mathrm{m}^{-2}$, coexisting with the culture for 85 days after sowing. The weeds had different interference on agronomic variables and each species competed with the culture of different nutrients. The wheat crop was more affected adversely when cultivated under infestation $E$. fosbergii and $G$. parviflora at increasing densities, highlighting that these weeds are adapted to lower temperatures.
\end{abstract}

Key words: Bidens pilosa, Emilia fosbergii, Galinsoga parviflora, competitive potential. 


\section{Introdução}

O trigo é a cultura mais plantada no mundo, ocupando o primeiro lugar em volume de produção (OLIVEIRA NETO; SANTOS, 2017). O Brasil possui uma demanda anual de 12 milhões de toneladas, produzindo o equivalente a 5,80 milhões, menos da metade de suas necessidades, importando desta forma a quantidade restante (SILVA et al., 2017). Dentre os fatores que limitam a expressão do potencial produtivo da cultura do trigo está a competição com as plantas daninhas (AGOSTINETTO et al., 2008; RIGOLI et al., 2008; BRAZ et al., 2006; SOUZA et al., 2006).

A competição pode ser caracterizada como a relação que se estabelece entre a cultura e as plantas daninhas na assimilação dos recursos disponíveis, principalmente água, luz, nutrientes e espaço (DEMÉTRIO et al., 2008). Essa relação competitiva entre a cultura e as plantas daninhas pode afetar a quantidade e a qualidade da produção, bem como a eficiência de aproveitamento dos recursos do ambiente (GALON et al., 2013; FERREIRA et al., 2008). As diferenças no poder competitivo normalmente estão relacionadas às características fisiológicas, associadas ao uso dos fatores do meio (MELO et al., 2006).

A capacidade de competir varia entre as espécies de plantas cultivadas. O milho (DUARTE et al., 2002), o girassol (ALVES et al., 2013), o trigo (AGOSTINETTO et al., 2008) e a soja (FERREIRA et al., 2009), por exemplo, possuem maior capacidade competitiva que culturas de baixo porte e reduzido poder de interceptação da luz solar, como a cebola, alho (SOARES et al., 2003) e cenoura (SOARES et al., 2010). Existem duas características inerentes às culturas que contribuem para colocá-las em vantagem sobre as plantas daninhas: a tolerância, habilidade de manter o rendimento ou supressão, capacidade de reduzir o crescimento das plantas daninhas. (CARVALHO et al., 2011; RIGOLI et al., 2009).

Dentre os fatores ligados à comunidade infestante, o tamanho e a diversidade da população são considerados dos mais importantes, de tal forma que, quanto maior a população maior a quantidade de indivíduos em disputa (FLECK et al., 2008). Em uma lavoura a população das plantas cultivadas geralmente é constante, ao passo que a das plantas daninhas varia de acordo com o toque de sementes no banco de diásporos do solo. Assim, nos estudos de competição não basta avaliar somente a população de plantas no processo competitivo, mas também é importante verificar a influência da variação na proporção entre as espécies (GALON et al., 2014).

Normalmente as plantas daninhas mais importantes e mais competitivas são aquelas pertencentes à mesma família botânica da cultura, pois elas têm necessidades de recursos similares e exploram praticamente o mesmo nicho que a cultura (AGOSTINETTO et al., 2008). A hipótese deste trabalho é baseada nas diferenças.

Diante do exposto, o estudo teve como objetivo avaliar o efeito da competição das espécies E. fosbergii, B. pilosa e G. parviflora, isoladas e em associação no crescimento das plantas de trigo em condição de campo.

\section{Material e Métodos}

O experimento foi conduzido a campo na área experimental do Campus JK da Universidade Federal dos Vales do Jequitinhonha e Mucuri (UFVJM), no município de Diamantina - MG. O trabalho foi desenvolvido no período de maio de 2013 a agosto de 2013, no inverno. A temperatura média foi de $17{ }^{\circ} \mathrm{C}$ na área do experimento, localizada a $1400 \mathrm{~m}$ de altitude, destacando-se que não foi registrada a ocorrência de precipitação na condução do experimento (período seco do ano), sendo necessária irrigação.

A semeadura do trigo foi realizada manualmente e com espaçamento entrelinhas de $0,20 \mathrm{~m}$ e distribuição de 240 sementes por $\mathrm{m}^{2}$. As unidades experimentais apresentaram dimensões de 6,0 x 3,0 m (18,0 m²), com área útil de $4 \times 2\left(8 \mathrm{~m}^{2}\right)$, tendo para a testemunha uma área de $3,0 \times 2,0\left(6,0 \mathrm{~m}^{2}\right)$ dentro da própria parcela (testemunha pareada).

O cultivar de trigo utilizado foi o BRS 264, de ciclo precoce, semeado no dia 02 de maio de 2013 em um Neossolo Quartzarênico órtico típico. A análise do solo, antes da implantação do experimento apresentou os seguintes valores: $\mathrm{pH}$ (água) de 5,8; $\mathrm{P}$ e $\mathrm{K}\left(\mathrm{mg} \mathrm{dm}^{-3}\right)$, 1,1 e 6,3 respetivamente; $\mathrm{SB}, \mathrm{Ca}, \mathrm{Mg}, \mathrm{Al}$ e $\mathrm{H}+\mathrm{Al}$ $\left(\right.$ cmolc $\left.\mathrm{dm}^{-3}\right), 1,1 ; 0,6 ; 0,5 ; 0,2$ e 2,4 respetivamente; $\mathrm{V}$ (\%), 32; MO, areia, argila e silte (dag $\left.\mathrm{kg}^{-1}\right), 0 \%, 86 \%$, $6 \%$ e $8 \%$ respectivamente, sendo devidamente corrigido e adubado. A adubação de plantio e cobertura foi realizada com base em Ribeiro et al. (1999), seguindose as recomendações técnicas para a cultura.

$\mathrm{O}$ experimento foi montado no esquema fatorial $4 \mathrm{x}$ 5, sendo o fator A representado pelas combinações: 1 . trigo competindo com Emilia fosbergii Nicolson (falsaserralha); 2. trigo competindo com Bidens pilosa L. (picão-preto); 3. trigo competindo com Galinsoga parviflora Cav. (botão-de-ouro) e o 4. trigo competindo com a combinação das três espécies. O fator B foi composto por quatro densidades de plantas daninhas mantidas manualmente $(0,00$ - testemunha capinada; 23; 46 e 66 plantas daninhas $\mathrm{m}^{-2}$ ), com quatro repetições. Considerando-se que nas parcelas com o plantio das três plantas daninhas (comunidade) a proporção destacada acima foi mantida igual para as espécies daninhas estudadas.

$\mathrm{O}$ experimento foi irrigado durante todo o período de condução, com a instalação de aspersores na área experimental. O turno de rega foi de quatro dias, com 
lâmina de $30 \mathrm{~mm}$, considerando o solo com alta porcentagem de areia (arenoso).

Após 85 dias da emergência das plantas de trigo (grão pastoso-enchimento dos grãos), avaliou-se as seguintes variáveis nas plantas de trigo: biomassa seca da parte aérea (BMSPA); biomassa seca da folha (BMSF); biomassa seca do caule (BMSC); biomassa seca das panículas (BMSP); estatura das plantas (EST) utilizando uma régua graduada em centímetros; comprimento das panículas (CPA) utilizando um paquímetro digital graduado em milímetros.

Os dados foram submetidos à análise de variância e interpretados utilizando a análise de regressão com significância de $5 \%$ pelo teste $\mathrm{F}$ utilizando o software SISVAR ${ }^{\circledR}$, versão 5.3

\section{Resultados e Discussão}

Ao avaliar a biomassa seca da parte aérea (BMSPA) de plantas de trigo cultivado em competição com as espécies E. fosbergii, B. pilosa, G. parviflora e a comunidade envolvendo as três espécies, verificou-se que com o incremento da densidade de plantas houve redução linear na biomassa seca da parte aérea (BMSPA) da cultura em todos os tratamentos avaliados (Tabela 1). Quando o trigo foi cultivado com diferentes densidades de E. fosbergii e de G. parviflora verificouse maior inclinação angular da curva, indicando maior agressividade dessas espécies em relação a $B$. pilosa e a população envolvendo as três plantas daninhas.

Os valores do coeficiente angular em ordem crescente (de inclinação) para a BMSPA foram -0,186; 0,$174 ;-0,160$ e $-0,144$ para os tratamentos E. fosbergii, G. parviflora, comunidade e B. pilosa, respectivamente, assim a espécie $B$. pilosa foi a que menos afetou negativamente a BMSPA das plantas de trigo (Tabela 1).

$\mathrm{Ni}$ et al. (2000) realizando ensaios com arroz inundado observaram que a velocidade de acúmulo de biomassa na parte aérea pela cultura até o início do afilhamento (cerca de 35 dias após a semeadura do arroz) foi a variável mais importante na predição do acúmulo de biomassa pelas plantas daninhas presentes na área de cultivo. Essa variável correlacionou-se com a formação de dossel com elevado potencial de captação de energia radiante, reduzindo a disponibilidade desse recurso às infestantes. Dessa forma a característica citada pode ser aplicada às plantas daninhas explicando a maior habilidade competitiva de E. fosbergii e $G$. parviflora em relação aos demais tratamentos.

Com relação à biomassa seca das folhas (BMSF) de trigo, não foi observado ajuste significativo da curva para a espécie E. fosbergii e a comunidade envolvendo o trigo e as três espécies daninhas (Tabela 2).

As plantas de trigo cultivadas nas parcelas infestadas com B. pilosa e nos tratamentos do trigo em competição com G. parviflora mostraram decréscimo na BMSF com aumento da população de plantas daninhas, sendo o coeficiente de inclinação menor quando realizado ajsute para a densidade de plantas de G. parviflora. Segundo Fleck et al. (2007), plantas de estatura e índice de área foliar elevados identificam culturas com bom potencial competitivo com as plantas daninhas. Cultivares de trigo com elevada habilidade competitiva apresentaram características como estatura elevada, folhas largas e decumbentes, crescimento vigoroso, abundante afilhamento e elevada cobertura do solo (LEMERLE et al., 2001).

Tabela 1. Biomassa seca da parte aérea (BMSPA) de plantas de trigo aos 85 dias após a emergência (grão pastoso - enchimento dos grãos) cultivado em competição com E. fosbergii, B. pilosa, G. parviflora e a comunidade envolvendo as três espécies, DiamantinaMG, 2013

\begin{tabular}{llcc}
\hline \multicolumn{1}{c}{ Espécie } & \multicolumn{1}{c}{ Equação* } & Inclinação & $\mathrm{R}^{2}$ \\
\hline Emilia fosbergii & $\hat{\mathrm{y}}=14,30^{*}-0,187^{*} \mathrm{X}$ & $-0,187$ & 0,97 \\
Bidens pilosa & $\hat{\mathrm{y}}=2,37^{*}-0,144^{*} \mathrm{X}$ & $-0,144$ & 0,70 \\
Galinsoga parviflora & $\hat{\mathrm{y}}=12,46^{*}-0,174^{*} \mathrm{X}$ & $-0,174$ & 0,40 \\
Comunidade & $\hat{\mathrm{y}}=12,79^{*}-0,160^{*} \mathrm{X}$ & $-0,160$ & 0,79 \\
\hline
\end{tabular}

*significativo a $5 \%$ de probabilidade de erro pelo teste $\mathrm{F}$.

Tabela 2. Biomassa seca das folhas (BMSF) de plantas de trigo aos 85 dias após a emergência (grão pastoso - enchimento dos grãos) cultivado em competição com E. fosbergii, B. pilosa, G. parviflora e a comunidade envolvendo as três espécies, Diamantina-MG, 2013

\begin{tabular}{lccc}
\hline Espécie & \multicolumn{1}{c}{ Equação $^{1}$} & Inclinação & $\mathrm{R}^{2}$ \\
\hline Emilia fosbergii & ---- & NS* & ---- \\
Bidens pilosa & $\hat{\mathrm{y}}=1,718^{*}-0,0116^{*} \mathrm{X}$ & $-0,0116$ & 0,76 \\
Galinsoga parviflora & $\hat{\mathrm{y}}=1,710^{*}-0,0220^{*} \mathrm{X}$ & $-0,0220$ & 0,88 \\
Comunidade & ----- & $\mathrm{NS}$ & ---- \\
\hline
\end{tabular}

\footnotetext{
${ }^{1 /}$ *significativo a $5 \%$ de probabilidade de erro pelo teste F. NS* não significativo a 5\% de probabilidade de erro pelo teste F.
} 
E. fosbergii e G. parviflora mostraram-se mais agressivas, promovendo maior decréscimo na biomassa seca do caule (BMSC), estimado por meio dos menores coeficientes angulares para essa variável (Tabela 3). Já nas parcelas cultivadas com $B$. pilosa e a combinação das três espécies, as plantas de trigo demonstraram decréscimos menos acentuados na BMSC com o incremento da população desta planta daninha.

Erasmo et al. (2003), trabalhando com Cyperus esculentus em plantas de arroz, constataram que densidades diferenciadas dessa espécie provocaram efeito sobre o perfilhamento de plantas de arroz irrigado e redução na biomassa seca do caule, após 60 dias de convivência com a cultura.

Observou-se redução da biomassa seca da panícula (BMSP) das plantas de trigo aos 85 dias após a emergência com o incremento da população de plantas daninhas para todos os tratamentos avaliados, sendo que, a espécie G. parviflora proporcionou redução mais severa na BMSP das plantas de trigo, apresentando maior coeficiente de inclinação linear da curva em relação aos demais tratamentos, entretanto, B. pilosa foi a espécie que menos afetou negativamente a BMSP (Tabela 4).
Plantas de trigo cultivadas em diferentes infestações de E. fosbergii apresentaram decréscimo na estatura (EST) com o incremento da população dessa planta daninha (Tabela 5). Em relação aos demais tratamentos, verificou-se coeficiente angular positivo, bem como aumento nos valores de EST com o acréscimo da densidade.

Dentre os tratamentos que mostraram acréscimo na EST das plantas do trigo, destaca-se G. parviflora que apresentou maior coeficiente angular, promovendo maior acréscimo em EST do trigo com o aumento da infestação dessa espécie. $\mathrm{O}$ aumento em estatura pode ser interpretado como uma forma da cultura evitar a competição por luz, ou seja, redução da biomassa seca total, do número de folhas e investimento em estatura para melhor interceptar a radiação luminosa (TAIZ; ZEIGER, 2014).

Agostinetto et al. (2008) observaram que a infestação de plantas de nabo e azevém promovem na cultura do trigo menor acúmulo de biomassa seca no período de convivência, possivelmente pela menor emissão e sobrevivência dos afilhos.

Tabela 3. Biomassa seca do caule (BMSC) de plantas de trigo aos 85 dias após a emergência (grão pastoso - enchimento dos grãos) cultivado em competição com E. fosbergii, B. pilosa, G. parviflora e a comunidade envolvendo as três espécies, Diamantina-MG, 2013

\begin{tabular}{llll}
\hline Espécie & Equação & Inclinação & $\mathrm{R}^{2}$ \\
\hline E. fosbergii & $\hat{\mathrm{y}}=7,47^{*}-0,0928^{*} \mathrm{X}$ & $-0,0928$ & 0,90 \\
B. pilosa & $\hat{\mathrm{y}}=6,04^{*}-0,0794^{*} \mathrm{X}$ & $-0,0794$ & 0,76 \\
G. parviflora & $\hat{\mathrm{y}}=6,53^{*}-0,0901^{*} \mathrm{X}$ & $-0,0901$ & 0,51 \\
Comunidade & $\hat{\mathrm{y}}=7,09^{*}-0,0868^{*} \mathrm{X}$ & $-0,0868$ & 0,85 \\
\hline
\end{tabular}

*significativo a $5 \%$ de probabilidade de erro pelo teste $\mathrm{F}$.

Tabela 4. Biomassa seca de panículas (BMSP) de plantas de trigo aos 85 dias após a emergência (grão pastoso - enchimento dos grãos) cultivado em competição com E. fosbergii, B. pilosa, G. parviflora e a comunidade envolvendo as três espécies, DiamantinaMG, 2013

\begin{tabular}{llll}
\hline Espécie & Equação & Inclinação & $\mathrm{R}^{2}$ \\
\hline E. fosbergii & $\hat{\mathrm{y}}=3,10^{*}-0,0300^{*} \mathrm{X}$ & $-0,0300$ & 0,97 \\
B. pilosa & $\hat{\mathrm{y}}=2,37^{*}-0,0283^{*} \mathrm{X}$ & $-0,0283$ & 0,58 \\
G. parviflora & $\hat{\mathrm{y}}=2,83^{*}-0,0400^{*} \mathrm{X}$ & $-0,0400$ & 0,66 \\
Comunidade & $\hat{\mathrm{y}}=2,56^{*}-0,0342 * \mathrm{X}$ & $-0,0342$ & 0,57 \\
\hline
\end{tabular}

*significativo a $5 \%$ de probabilidade de erro pelo teste $\mathrm{F}$

Tabela 5. Estatura (EST) de plantas de trigo aos 85 dias após a emergência (grão pastoso - enchimento dos grãos) cultivado em competição com E. fosbergii, B. pilosa, G. parviflora e a comunidade envolvendo as três espécies, Diamantina-MG, 2013

\begin{tabular}{llll}
\hline Espécie & Equação & Inclinação & $\mathrm{R}^{2}$ \\
\hline E. fosbergii & $\hat{\mathrm{y}}=76,77^{*}-0,0906^{*} \mathrm{X}$ & $-0,0906$ & 0,70 \\
B. pilosa & $\hat{\mathrm{y}}=70,47^{*}+0,127^{*} \mathrm{X}$ & $+0,1270$ & 0,68 \\
G. parviflora & $\hat{\mathrm{y}}=76,81^{*}+0,0347^{*} \mathrm{X}$ & $+0,0347$ & 0,56 \\
Comunidade & $\hat{\mathrm{y}}=77,00^{*}+0,0260^{*} \mathrm{X}$ & $+0,0260$ & 0,67 \\
\hline
\end{tabular}

\footnotetext{
*significativo a $5 \%$ de probabilidade de erro pelo teste $\mathrm{F}$.
} 
Nos tratamentos de competição da cultura com $B$. pilosa, G. parviflora e com a comunidade de plantas observou-se que os cultivares de trigo apresentaram maior estatura de planta no período de convivência com as infestantes, talvez pelo fato da conversão de assimilados ter sido revertida ao colmo principal. Entretanto, a cultura em crescimento juntamente com densidades crescentes de E. fosbergii mostrou comportamento inverso, ou seja, redução da EST com o incremento da densidade, fato que pode estar relacionado à competição de recursos no solo (Tabela 5). Lamego et al. (2013) trabalhando com diferentes cultivares de trigo infestado com as plantas daninhas Triticum aestivum, Lolium multiflorum, Raphanus raphanistrum não observaram diferença, na média, entre os cultivares de trigo para a estatura nos períodos de 15 e 30 dias após a semeadura.

Em condição de competição por luz plantas de trigo tenderam a aumentar sua estatura; segundo Almeida e Mundstock (2001) a luz é determinante na capacidade de afilhamento e produtividade da cultura do trigo. Os cereais de inverno, quando em competição por luz, aumentam o direcionamento de fotoassimilados na formação de colmos, ou seja, ocorre estiolamento das plantas com o objetivo de maior captação de luz, com menor investimento de energia para o afilhamento, desenvolvimento de área foliar e de biomassa seca e crescimento radicular; até mesmo a produtividade de grãos pode ser afetada pois a planta investe mais energia no órgão com maior déficit nutricional em contraponto aos demais (GALON et al., 2011).

Com relação ao comprimento das panículas (CPA) de trigo não se observou alteração nos valores dessa variável com o incremento da população nas parcelas em que a cultura foi cultivada com E. fosbergii, $B$. pilosa e a comunidade; para $G$. parviflora não foi possível ajuste de uma equação linear (Tabela 6). Duarte et al. (2002) observaram que o comprimento de panículas e o peso de grãos não se alteraram quando a capina da cultura do milho foi realizada somente até o pendoamento, em comparação com a eliminação total das plantas daninhas durante todo o ciclo da cultura.

Dessa forma, pode-se afirmar que existe diferença na capacidade competitiva entre as plantas daninhas estudadas com a cultura do trigo. Entre elas, E. fosbergii e G. parviflora mostraram-se mais agressivas à cultura para a maior parte das variáveis estudadas, como altura de planta, biomassa seca e biomassa seca da parte aérea. Bidens pilosa apresentou menor tendência de redução das variáveis avaliadas na cultura do trigo com o incremento da densidade. No entanto, a cultura crescendo infestada pelas três espécies simultaneamente mostrou menor decréscimo nos valores da maioria das variáveis quando comparado aos tratamentos em que a cultura competia com E. fosbergii e G. parviflora.

Uma das respostas esperadas era um efeito aditivo no crescimento do trigo, devido às diferenças na habilidade competitiva das espécies pelos recursos presentes no meio, entretanto, essas respostas podem ser mais complexas se considerarmos a relação de plantas de diferentes espécies crescendo em comunidade. É possível que a competição interespecífica tenha promovido menor efeito negativo sobre a cultura do trigo.

Plantas de picão-preto apresentam maior capacidade competitiva pelo fósforo (SANTOS; CURY, 2011); a braquiária apresenta em muitos casos alta capacidade de absorção de nitrogênio (CURY et al., 2012). Nessas situações o cultivo simultâneo dessas duas espécies competindo com a cultura da mandioca promoveu maior redução nas características fitotécnicas da cultura em comparação com o cultivo isolado (PEREIRA et al., 2012).

No presente trabalho, apesar de não ter sido realizada a análise nutricional há possibilidade da densidade de uma mesma espécie responder por déficit de determinado nutriente no solo e, dessa forma, comprometer os componentes de rendimento da cultura avaliados.

Ainda não existem trabalhos que relatam sobre o nível de dano econômico de plantas daninhas na cultura do trigo no Brasil e, no mundo, são poucos os relatos. Pester et al. (2000), em estudo sobre o Nível de Dano Econômico de Secale cereale na cultura do trigo nos EUA observaram que quando esta planta daninha estava em densidade de 60 plantas $/ \mathrm{m}^{2}$, valor igual ao adotado na maior densidade do presente trabalho, a redução no rendimento do trigo foi superior a $80 \%$.

Tabela 6. Comprimento de panículas (CPA) de plantas de trigo aos 85 dias após a emergência (grão pastoso - enchimento dos grãos) cultivado em competição com E. fosbergii, B. pilosa, G. parviflora e a comunidade envolvendo as três espécies, Diamantina-MG, 2013.

\begin{tabular}{llll}
\hline Espécie & Equação & Inclinação & $\mathrm{R}^{2}$ \\
\hline E. fosbergii & $\hat{\mathrm{y}}=8,34$ & 0,00 & 0,90 \\
B. pilosa & ----- & $\mathrm{NS} *$ & ---- \\
G. parviflora & $\hat{\mathrm{y}}=8,00$ & 0,00 & 0,98 \\
Comunidade & $\hat{\mathrm{y}}=8,45$ & 0,00 & 0,98 \\
\hline
\end{tabular}

${ }^{1 /}$ *significativo a $5 \%$ de probabilidade de erro pelo teste F. NS* não significativo a 5\% de probabilidade de erro pelo teste F. 
Zanin et al. (1993), em ensaio conduzido na Itália, observaram que a competição em densidades de 60 plantas $/ \mathrm{m}^{2}$ reduziu o rendimento do trigo em aproximadamente $35 \%$ e $16 \%$ quando em convivência com Galium aparine e Alopecurus myosuroides, respectivamente.

Gherekhloo et al. (2010) no Irã, analisando o Nível de Dano Econômico na cultura do trigo em dois ambientes observaram que no primeiro ambiente as plantas que infestaram a cultura foram: Avena ludoviciana, Chenopodium album, Solanum nigrum, Stellaria holosea, Fumaria sp., Polygonum aviculare, Sonchus sp., e Convolvolus spp. Na segunda região foram observadas a presença de: A. ludoviciana, Erysimum spp., P. aviculare, Rapistrum rugosum, $C$. album, Salsola kali, e Sonchus spp. Houve redução de $52 \%$ e $47 \%$ do rendimento do trigo quando as plantas daninhas infestaram na densidade de 60 plantas $\mathrm{m}^{-2}$.

Os resultados do presente estudo demostram os danos causados pela convivência de plantas de trigo com plantas daninhas e indicam a necessidade de trabalhos futuros que abordem sobre o prejuízo econômico quando esta cultura é infestada por diferentes plantas daninhas.

\section{Conclusões}

A cultura do trigo foi afetada negativamente quando cultivado sob infestação de E. fosbergii e G. parviflora em densidades crescentes, inclusive em comparação aos efeitos da competição em comunidades. Bidens pilosa foi a espécie que menos afetou o crescimento da cultura em comparação com as demais espécies testadas.

\section{Agradecimentos}

Os autores agradecem a Coordenação de Aperfeiçoamento de Pessoal de Nível Superior (CAPES) e Fundação de Amparo à Pesquisa do Estado de Minas Gerais (FAPEMIG) pelo apoio financeiro e as bolsas concedidas.

\section{Referências Bibliográficas}

AGOSTINETTO; D.; RIGOLI, R. P.; SCHAEDLER, C. E.; TIRONI, S. P.; SANTOS, L. S. Período crítico de competição de plantas daninhas com a cultura do trigo. Planta Daninha, Viçosa-MG, v. 26, n. 2, p. 271-278, 2008.

ALMEIDA, L. A.; MUNDSTOCK, C. M. A qualidade da luz afeta o afilhamento em plantas de trigo, quando cultivadas sob competição. Ciência Rural, Santa Maria-RS, v. 31, n. 3, p. 401-408, 2001.

ALVES, G. S.; TARTAGLIA, F. L.; ROSA, J. C.; LIMA, P. C.; CARdoso, G. D.; BELTRÃO, N. E. M. Períodos de interferência das plantas daninhas na cultura do girassol em
Rondônia. Revista Brasileira de Engenharia Agrícola e Ambiental, Campina Grande-PB, v. 17, n. 3, p. 275-282, 2013.

BRAZ, A. J. B. P.; PROCÓPIO, S. O.; CARGNELUTTI FILHO, A.; SILVEIRA, P. M.; KLIEMANN, H. J.; COBUCCI, T.; BRAZ, G. B. P. Emergência de plantas daninhas em lavouras de feijão e de trigo após o cultivo de espécies de cobertura de solo. Planta Daninha, Viçosa-MG, v. 24 , n. 4 , p. 621-628, 2006.

CARVALHO, F. P.; SANTOS, J. B.; CURY, J. P.; SILVA, D. V.; BRAGA, R. R.; BYRRO, E. C. M. Alocação de biomassa seca e capacidade competitiva de cultivares de milho com plantas daninhas. Planta Daninha, Viçosa-MG, v. 29, n. 2, p. 373-382, 2011.

CURY, J. P.; SANTOS, J. B.; SILVA, E. B.; BYRRO, E. C. M.; BRAGA, R. R.; CARVALHO, F. P.; SILVA, D. V. Acúmulo e partição de nutrientes de cultivares de milho em competição com plantas daninhas. Planta Daninha, ViçosaMG, v. 30, p. 287-296, 2012.

DEMÉTRIO, C. S.; FORNASIERI FILHO, D.; CAZETTA, J. O.; CAZETTA, D. A. Desempenho de híbridos de milho submetidos a diferentes espaçamentos e densidades populacionais. Pesquisa Agropecuária Brasileira, BrasíliaDF, v. 43, n. 12, p. 1691-1697, 2008.

DUARTE, N. F.; SILVA, J. B.; SOUZA, I. F. Competição de plantas daninhas com a cultura do milho no município de Ijaci, MG. Ciência e Agrotecnologia, Lavras-MG, v. 26, n. 5, p. 983-992, 2002.

ERASMO, E. A. L.; COSTA, N. V.; PINHEIRO, L. L. A.; SILVA, J. I. C.; TERRA, M.; SARMENTO, R. A.; CUNHA, A. M.; GARCIA, S. L. R. Efeito da densidade e dos períodos de convivência de Cyperus esculentus na cultura do arroz irrigado. Planta Daninha, Viçosa-MG, v. 21, n. 3, p. 381-383, 2003.

FERREIRA, E. A.; CONCENÇO, G.; SILVA, A. A.; REIS, M. R.; VARGAS, L.; VIANA, R. G.; GUIMARÃES, A. A.; GALON, L. Potencial competitivo de biótipos de azevém (Lolium multiflorum). Planta Daninha, Viçosa-MG, v. 26, n. 2, p. 261-269, 2008.

FERREIRA, E. A.; SILVA, A. F.; FRANÇA, A. C.; GALON, L.; CONCENÇO, G.; FERREIRA, F. A.; ASPIAZÚ, I.; SILVA, A. A. Efeitos de períodos de competição nas características morfológicas de grãos de soja. Revista Trópica - Ciências Agrárias e Biológicas, Chapadinha-MA, v. 3, n. 2, p. 53-60, 2009.

FLECK, N. G.; AGOSTINETTO, D.; GALON, L.; SCHAEDLER, C. E. Competitividade relativa entre cultivares de arroz irrigado e biótipo de arroz-vermelho. Planta Daninha, Viçosa-MG, v. 26, n. 1, p. 101-111, 2008.

FLECK, N. G.; LAMEGO, F. P.; SCHAEDLER, C. E.; FERREIRA, F. B. Resposta de cultivares de soja à competição com cultivar simuladora da infestação de plantas concorrentes. Scientia Agricola, Piracicaba-SP, v. 8, n. 3, p. 213-218, 2007.

GALON, L.; FERREIRA, E. A.; CONCENÇO, G.; SILVA, A. A.; SILVA, D. V.; SILVA, A. F.; ASPIAZÚ, I.; VARGAS, L. Características fisiológicas de biótipos de Conyza bonariensis resistentes ao glyphosate cultivados sob 
competição. Planta Daninha, Viçosa-MG, v. 31, n. 4, p. 859866, 2013.

GALON, L.; GUIMARÃES, S.; LIMA, A. M.; RADUNZ, A. L.; BEUTLER, A. N.; BURG, G. M.; ZANDONÁ, R. R.; PERIN, G. F.; BASTIANI, M. O.; BELARMINO, J. G.; RADUNZ, L. L. Interação competitiva de genótipos de arroz e papuã. Planta Daninha, Viçosa-MG, v. 32, n. 3, p. 533-542, 2014.

GALON, L.; TIRONI, S. P.; ROCHA, P. R. R.; CONCENÇO, G.; SILVA, A. F.; VARGAS, L.; SILVA, A. A.; FERREIRA, E. A.; MINELlA, E.; SOARES, E. R.; FERREIRA, F. A. Habilidade competitiva de cultivares de cevada convivendo com azevém. Planta Daninha, Viçosa-MG, v. 29, n. 4, p. 771$781,2011$.

GHEREKHLOO, J.; NOROOZI, S.; MAZAHERI, D.; GHANBARI, A.; GHANNADHA, M. R.; VIDAL, R. A., DE PRADO, R. Multispecies weed competition and their economic threshold on the wheat crop. Planta Daninha, Viçosa-MG, v. 28, n. 2, p. 239-246, 2010.

LAMEGO, F. P.; RUCHEL, Q.; KASPARY, T. E.; GALLON, M.; BASSO, C. J.; SANTI, A. L. Habilidade competitiva de cultivares de trigo com plantas daninhas. Planta Daninha, Viçosa-MG, v. 31, n. 3, p. 521-531, 2013.

LEMERLE, D.; GILL, G. S.; MURPHY, C. E.; WALKER, S. R.; COUSENS, R. D.; MOKHTARI, S.; PELTZER, S. J.; COLEMAN, R.; LUCKETT, D. J. Genetic improvement and agronomy for enhanced wheat competitiveness with weeds. Australian Journal of Agricultural Research, Oxford, v. 52, n. 1, p. 527-548, 2001.

MELO, P. T. B. S.; SCHUCH, L. O. B.; ASSIS, F. N.; CONCENÇO, G. Comportamento de populações de arroz irrigado em função das proporções de plantas originadas de sementes de alta e baixa qualidade fisiológica. Revista Brasileira de Agroecologia, Bento Gonçalves-RS, v. 12, n. 1, p. 37-43, 2006.

NI, H.; MOODY, K.; ROBLES, R. P.; PALLER, Jr. E. C.; LALES, J. S. Oryza sativa plant traits conferring competitive ability against weeds. Weed Science, Lawrence-Kansas, v. 48, n. 2, p. 200-204, 2000.

OLIVEIRA NETO, A. A.; SANTOS, C. M. R. A cultura do Trigo. Brasília-DF: CONAB, 2017, 218 p.

PEREIRA, G. A. M.; LEMOS, V. T.; SANTOS, J. B.; FERREIRA, E. A.; SILVA, D. V.; OLIVEIRA, M. C.; MENEZES, C. W. G. Crescimento da mandioca e plantas daninhas em resposta à adubação fosfatada. Revista Ceres, Viçosa-MG, v. 59, n. 5, p. 716-722, 2012.
PESTER, T. A.; WESTRA, P.; ANDERSON, R. L.; LYON, D. J.; MILLER, S. D.; STAHLMAN, P. S.; NORTHAM, F. E.; GAIL A. WICKS, G. A. Secale cereale interference and economic thresholds in winter Triticum aestivum. Weed Science, Washington-DC, v. 48, n. 6, p. 720-727, 2000.

RIBEIRO, A. C.; GUIMARÃES, P. T. G.; ALVAREZ V, V. $H$. Recomendações para o uso de corretivos e fertilizantes em minas gerais $5^{a}$ aproximação. Viçosa-MG: CFSEMG, 1999. $359 \mathrm{p}$.

RIGOLI, R. P.; AGOSTINETTO, D.; SCHAEDLER, C. E.; DAL MAGRO, T.; TIRONI, S. Habilidade competitiva relativa do trigo (Triticum aestivum) em convivência com azevém (Lolium multiflorum) ou nabo (Raphanus raphanistrum). Planta Daninha, Viçosa-MG, v. 27, n. 1, p. 41-47, 2008

RIGOLI, R. P.; AGOSTINETTO, D.; VAZ DA SILVA, J. M. B.; FONTANA, L. C.; VARGAS, L. Potencial competitivo de cultivares de trigo em função do tempo de emergência. Planta Daninha, Viçosa-MG, v. 27, n. 1, p. 41-47, 2009.

SANTOS, J. B.; CURY, J. P. Picão-preto: uma planta daninha especial em solos tropicais. Planta Daninha, Viçosa-MG, v. 29, n. spe, p. 1159-1171, 2011.

SILVA, S. R.; BASSOI, M. C.; FOLONI, J. S. S. Informações técnicas para trigo e triticale, Safra-2017. 1. ed. Passo Fundo-RS: Embrapa Trigo, 2017. 241 p. Disponível em: <http://www.cnpt.embrapa.br/culturas/trigo/index.htm>. Acesso em: 12 abr. 2017.

SOARES, D. J.; PITELLI, R. A.; BRAZ, L. T.; GRAVENA, R.; TOLEDO, R. E. B. Períodos de interferência das plantas daninhas na cultura de cebola (Allium cepa) transplantada. Planta Daninha, Viçosa-MG, v. 21 n. 3, p. 387-396, 2003.

SOARES, I. A. A.; FREITAS, F. C. L.; NEGREIROS, M. Z.; FREIRE, G. M.; AROUCHA, E. M. M.; GRANGEIRO, L. C.; LOPES, W. A. R.; DOMBROSKI, J. L. D. Interferência das plantas daninhas sobre a produtividade e qualidade de cenoura. Planta Daninha, Viçosa-MG, v. 28 n. 2, p. 247-254, 2010.

SOUZA, L. S.; VELINI, E. D.; MARTINS, D.; ROSOLEM, C. A. Efeito alelopático de capim-braquiária (Brachiaria decumbens) sobre o crescimento inicial de sete espécies de plantas cultivadas. Planta Daninha, Viçosa-MG, v. 24, n. 4, p. $657-668,2006$.

TAIZ, L.; ZEIGER, E. Fisiologia vegetal, 8. ed. Porto AlegreRS: Artmed, 2014, 848 p.

ZANIN, G.; BERTI, A.; TONIOLO, L. Estimation of economic thresholds for weed control in winter wheat. Weed Research, v. 33, n. 1, p. 459-467, 1993. 